\title{
ALGUNOS EJEMPLOS DE LA PERVIVENCIA DE VIEJOS CUENTOS ORIENTALES EN LA LITERATURA ESPAÑOLA DE LOS SIGLOS XVI Y XVII
}

LOLA LÓPEZ DIAZ

Profesora-Tutora de la UNED, Madrid

«Dígote de verdad -respondió D. Quijote- que tú has contado una de las más nuevas consejas, cuento o historia, que nadie pudo pensar en el mundo, y que tal modo de contarla ni dejarla, jamás se podrá ver ni habrá visto en toda la vida, aunque no esperaba yo otra cosa de tu buen discurso.» (Quijote I.20)

¿Por qué se burla D. Quijote de la «novedad» de la historia que le ha contado Sancho? ¿De qué historia se trata? Oigámosla:

«Sucedio -dijo Sancho- que el pastor puso por obra su determinación, y, antecogiendo sus cabras, se encaminó por los campos de Extremadura, para pasarse a los reinos de Portugal. La Torralba, que lo supo, se fue tras él [...] el pastor llego con su ganado a pasar el río Guadiana, y en aquella sazón iba crecido y casi fuera de madre, y por la parte que llegó no había barca ni barco, ni quien le pasase a él y a su ganado de la otra parte, de lo que se congojo mucho, porque vera que la Torralba venía ya muy cerca [...] mas, tanto anduvo mirando, que vio un pescador, que tenía junto a sí un barco, tan pequeño, que solamente podían caber en él una persona y una cabra [...] Entró el pescador en el barco y pasó una cabra; volvió y pasó otra; tornó a volver, y 
tornó a pasar otra. Tenga vuestra merced cuenta de las cabras que el pescador va pasando, porque si se pierde una de la memoria se acabará el cuento...» (Quijote 1.20)

¡Pobre Sancho!... ¡Pretender sorprender a su amo con un cuento que ya aparece recogido, en el siglo XII, en la Disciplina clericalis!... Claro que según Pedro Alfonso las ovejas son dos mil y con ellas y su viaje en barca intenta el «fablador» hacer dormir al rey, su amo...1.

Pero no es solamente Sancho el que trae a colación viejas consejas, cuentos e historias. Aparecen a cada paso en novelas, en comedias, en muchas páginas de la mejor literatura de los siglos XVI y XVII. Así, siguiendo con Cervantes, en el entremés $E l$ viejo celoso nos encontramos con una versión del «Ejemplo del lienzo», procedente también de la Disciplina clericalis. Se trata del engaño que sufre un marido que llega al hogar conyugal en el momento en que su suegra, su mujer y el amante de ésta se disponen a almorzar. Ante lo comprometido de la situación, el amante se esconde y la suegra se pone a enseñar a su yerno un lienzo tejido por ella y por su hija, extendiéndolo de manera que el mozo pueda fugarse sin ser descubierto. En el entremés cervantino la artimaña tiene la función contraria, es decir, en vez de servir para camuflar al amante que huye, sirve para introducir en casa del celosísimo Cañizares, un joven con el que se solace Lorenza, su insatisfecha esposa: Ortigosa, la celestinesca vecina, se presenta portando un guadamecí con la falsa pretensión de vendérselo al viejo, y al alzarlo para mostrárselo, «entra por detrás dél un galán»2. Y cuando Cañizares se dispone a entrar en la habitación en la que yacen su infiel esposa y el susodicho galán, es recibido con una bacía de agua en los ojos, las mujeres de la casa acuden a limpiarle y el muchacho se escapa sin problemas. Esta nueva treta está en la línea de otro ejemplo de la Disciplina, el «Ejemplo del vendimiador» que cuenta cómo un marido vuelve de vendimiar antes de tiempo porque se ha herido en un ojo con un sarmiento, y cómo su mujer, que está divirtiéndose con su querido, se pone a hacerle «melezina" en el ojo sano para preservarlo del contagio. La «melezina" consiste en chupar el dicho ojo sano del vendimiador, impidiéndole así ver la huida del intruso. Aunque quizá exista un paralelismo mayor con el relato del Corbacho (II, X), en que una mujer, en idénticas circunstancias, ciega a su marido proyectándole, con uno de sus pechos, un chorro de leche. Por razones

1 «Ejemplo del rústico», PEDRo ALFOnso, Disciplina clericalis, Ed. Angel González Palencia, (Madrid-Granada: CSIC, 1948), 125-126.

2 Miguel de Cervantes, Entremeses, Ed. Eugenio Asensio, (Madrid: Castalia, 1970), 213; cfr. «Ejemplo del lienzom, Pedro Alfonso, 121. 
obvias, Cervantes no podía llevar esta situación a la escena, de ahí quizá que la sustituyera por el bacín3.

Otro viejo cuento lo encontramos en La Galatea, en cuyo episodio de Silerio y Timbrio (Libros II y III), recoge Cervantes un motivo que desde su aparición en la Disciplina clericalis gozaba de enorme difusión. Se trata del «Ejemplo del amigo íntegro», en el que se nos cuenta la siguiente historia:

Dos mercaderes, uno de Egipto y otro de Baldach son amigos sin haberse visto (a través de cartas, mensajeros, etc.). El de Baldach va a Egipto donde, a pesar de la magnífica acogida que le dispensa su amigo, se pone enfermo y los médicos le diagnostican «mal de amor». El egipcio, a fin de ayudarle a combatir la enfermedad, le muestra a sus esclavas, a sus hijas y, finalmente, a su novia que es, precisamente, de la que el de Baldach se encapricha. El huésped, sin dudarlo un momento, se la concede en matrimonio dotándola muy ricamente y el de Baldach se vuelve tan contento a su país. Por una serie de avatares, el egipcio se arruina y decide ir a Baldach. Cuando llega a la ciudad es de noche y no se atreve a ir a casa de su amigo por lo que se refugia en una mezquita. Ocurre que cerca de allí matan a un hombre y la policía coge al egipcio que, harto de su mísera existencia, se declara culpable. Cuando al día siguiente le llevan al suplicio, su amigo le ve y se inculpa del crimen para liberarlo. El verdadero asesino que está presente, conmovido, confiesa su culpa. El rey les perdona a los tres y el amigo rico reparte todas sus riquezas con el amigo pobre.

Hasta aquí Pedro Alfonso. En la versión cervantina, Silerio, por una serie de circunstancias que no vienen al caso, encuentra a su amadísimo amigo Timbrio, al que buscaba, en el preciso momento en que es conducido al patíbulo; sin dudarlo un momento, empuña la espada y lo libera, quedando él herido y encarcelado en su lugar. Tras una serie de peripecias, nos encontramos a los dos amigos en Nápoles: Timbrio enfermo de amor por culpa de una hermosa napolitana y Silerio tratando de ayudarle y enamorándose de la dama en cuestión, lo que da lugar a mutuas, continuas y conmovedoras pruebas de amistad.

Pero no es Cervantes el único que se deja cautivar por la belleza de la historia. A partir sobre todo de la adapción que hace Boccaccio en el Decameron (historia de Tito y Gisipo, Jornada X, VIII), son muchos los autores que dentro y fuera de nuestras fronteras se hacen eco del tema. Por ceñimos al periodo que nos ocupa, aparte de en El Patrañuelo de Timoneda, lo encontramos en el El curial del Parnaso de Matías de los Reyes, en La boda entre dos maridos de Lope de Vega, en La desgraciada amistad de Pérez de Montalbán,

3 «Ejemplo del vendimiador», PEDro Alfonso, 119-120. Sobre este tema, vid. GEORGES CIRLOT, «Gloses sur les 'maris jaloux' de Cervantes»,Bulletin Hispanique 31 (1929), 1-74; LoLA LÓPEZ DIAZ, Diez maneras de engañar al marido con éxito, LEER 68-69 (1993), 29-32. 
en el David Perseguido de Cristobal Lozano... (de donde, dos centurias más tarde, lo tomará José Zorrilla para su leyenda Dos hombres qenerosos) 4.

Y ya que lo hemos mencionado, detengámonos un momento en Lope de Vega, pues son muchas las creaciones del Fénix a las que se asoman viejos cuentos orientales. Citaremos, a título de ejemplo, El milagro por los celos en cuya jornada III encontramos al lacayo Silveira contando aquello de

«Un perro una vez pasaba

otro río como el Duero

$y$ un pedazo de carnero

entre los dientes llevaba.

La sombra, que no era poca,

dentro de las aguas vio;

y por cogerla soltó

lo que llevaba en la boca.

Fue a asirla, y su desvario

el perro al instante vio;

volvio a su carne, y hallo

que se la llevo el tal río.»s.

Versión lopesca del conocido cuento del Calila e Dimna en el que

«un can que dizen que iva por un río et llevava una pieça de carne en la boca, et vido la sonbra que fazía, et por abarcar la sombra, abrio la boca et cayosele la que levava, et llevógela el agua et non fa116 cosa ninguna. $\$$.

Del «Ejemplo de la serpiente de oro» de la Disciplina clericalis procede un episodio de la Jornada II de las Audiencias del rey don Pedro. Pedro Alfonso recoge el relato del hombre rico que pierde una bolsa conteniendo dinero y una serpiente de oro y ofrece cien dineros al que la encuentre; un hombre

4 «Ejemplo del amigo íntegron, PEDRo ALFONSO, 98-102. La bibliografia sobre el tema es abundante; vid., entre otros, J.B. AvalLE-ARCE, «El cuento de los dos amigos», Nuevos deslindes cervantinos (Barcelona: Ariel, 1975), 153-211; H. SCHWARZBAUM, «International Folklore Motifs in Petrus Alphonsi's Disciplina Clericalis», Sefarad XXI (1961), 289-294; L. SORIERI, Boccaccio's Story of Tito e Gisipo in European Literature (New York: Institute of French Studies, 1937); J.F.L. RASCHEN, «Earlier and Later Versions of the Friendship Theme», Modern Philology XVII (19191920), 49-53.

5 LOPE DE VEGA, «El milagro por los celosn, Obras de Lope de Vega, BAE 213, 263.

6 \&El mercader que se entretuvo oyendo cantares», Calila e Dimna, Ed. J.M. Cacho Blecua y María Jesús Lacarra, (Madrid: Castalia, 1984), 114. 
pobre la encuentra y la devuelve y, en lugar de recompensarle, el rico dice que la bolsa contenía dos serpientes de oro y que el pobre le ha robado una, por lo que le lleva a los tribunales. Gracias a la ayuda de un agudo filósofo, los hechos se esclarecen y cada uno recibe su merecido. Pero veamos cómo lo cuenta Lope:

Leñador:

«Yo me sustento, gran señor, y a mi familia, que mujer e hijos tengo, de vender cargas de leña con un cansado jumento.

[...]

Madrugué anteayer, señor, pensando volver más presto, y en el camino de santo Lázaro, de llagas lleno, pisé una cosa muy dura; bajéme por ella al suelo, y halle cincuenta doblas marroquíes, que pudieron remediar mi pobre casa; pero como yo me precio de cumplir lo que Dios manda restituyendo lo ajeno, vine a casa, y mi mujer, que tiene honrados respetos, me dijo las pregonase; $y$ apenas intento hacello cuando las doblas pedía a voces un pregonero; también prometió de dar de hallazgo, si fuere cierta, diez doblas; agradecí $\tan$ honrado ofrecimiento a este mercader, que dijo haber perdido el dinero; lo entregue, y pidiendo yo las diez doblas con denuedo dijo: 'yo perdí sesenta; cincuenta traeis, buen viejo; esas diez doblas que faltan por vuestro hallazgo os dejo.' 
Y juro, señor invicto, por los Santos Evangelios, que una dobla no tome.

Rey:

Mercader:

¿Qué respondéis vos?

Que fueron

sesenta las que perdí

Rey:

y que cincuenta os ha devuelto.

Mercader:

Quedándose con las diez que le prometí primero.

Rey:

Mercader:

¿Juráislo?

Rey:

Señor, si juro.

Dadle al momento el talego;

que si perdisteis sesenta

doblas, y cincuenta fueron

las que dice que halló, ese dinero no es vuestro, y no es razón que pidáis a nadie lo que es ajeno; llevad, buen viejo, las doblas; y si acaso en algún tiempo os halláredes sesenta, se las daréis a este necio.»?.

Otra versión de esta historia la tenemos en El Patrañuelo (patraña VI) de Timoneda8. Pero siguiendo con Lope, la argucia que, en la Jornada I de Las paces de los reyes, utiliza Dominguillo para traicionar a su señor don Lope de Arenas y pasarse al bando del rey, enemigo a la sazón de don Lope, consistente en una pelea amañada con un soldado del monarca, recuerda según María Rosa Lida, el cuento de «El religioso y los tres ladrones» del Calila. Aunque el paralelismo, a mi entender, no está tan claro, pues en el Calila el traidor es

7 LOPE DE VEGA, «Audiencias del Rey Don Pedro», Obras de Lope de Vega, BAE 212, 183 184. Cfr. «Ejemplo de la serpiente de oro», Pedro Alfonso, 140-142.

8 Vid. JoAn Timoneda, El Patrafíuelo, Ed. José Romera Castillo, 2a ed., (Madrid: Cátedra, 1986), 154-160. 
el lesionado y en la obra de Lope el traidor lesiona a un tal Pero Díez que se ofrece voluntario. Y es que el resumen que hace Lida del episodio resulta algo confuso, pues dice que Dominguillo «para ganar la confianza de don Lope de Arenas, gobernador del Castillo de Zurita, finge reñir con un soldado en los reales de su enemigo y se acoge al castillo"'. Y la verdad del cuento es que Dominguillo se acoge al castillo de $D$. Lope, su señor y protector, después de la fingida pelea con el soldado del rey, pelea que sirve para encubrir su trato con éste y que le permite entrar al castillo sin levantar sospechas.

Y para terminar este pequeño apartado dedicado a Lope, recordemos que compuso una comedia titulada Barlán y Josafá, basada en la narración del mismo título que, como se sabe, fue una de las obras de procedencia oriental de mayor influencia en la Europa cristiana, obra que también debió de interesar a Calderón de la Barca pues su huella puede rastrearse en la $L a$ vida es sueño. Pero no voy a determe en este punto, que es de sobra conocido; sí quiero, en cambio, señalar la presencia de uno de los cuentos intecalados en el Barlaam en la comedia de Calederon titulada En esta vida todo es verdad y mentira. Se trata del cuento del principe al que, tras pasar los doce primeros años de su vida encerrado e incomunicado (por culpa, como siempre, de una predicción astrológica), se le muestran las realidades del mundo y entre ellas las mujeres. El muchacho pregunta por el nombre de éstas y su mentor le dice que se llaman «demonios que engañaban a los hombres». Cuando el rey pregunta a su hijo qué es lo que más le ha gustado, el chico contesta que los demonios que engañan a los hombres «porque de todo lo que he visto hoy nada hay que haya cautivado más mi alma que aquello»10. En la comedia calderoniana, Heraclio, que había crecido en los bosques, sin contacto alguno con mujeres, al ver por primera vez una, exclama:

Cintia:

«QQué bello animal!

\section{¡Qué fiera}

tan espantosa!

Heraclio:

$$
\begin{aligned}
& \text { ¡Divino } \\
& \text { asombro! }
\end{aligned}
$$

Cintia:

$$
\text { ¡Horrible presencia! }
$$

9 Marta Rosa LidA, El cuento Popular y otros ensayos (Buenos Aires: Losada, 1976), 58. Cfr. Lope de Vega, «Las paces de los reyes*, Comedias escogidas de Fray Lope Félix de Vega Crapio, BAE 41, 571-572, y «El religioso y los tres ladrones*, Calila e Dimna, 236-238.

10 Barlaam y Josafat, Ed. Pedro Bádenas de la Peña, (Madrid: Siruela, 1993), 224. 
Heraclio:

Cintia:

¡Qué hermosura!

Heraclio:

$$
\text { ¡Qué fiereza! }
$$

Cizaña de dos sentidos

Pues con hurtados despojos,

Antes de verte los ojos

Te miraron los ofdos, ¿Quién eres, que suspendidos Los dejas?

Cintia:

¿Quién he de ser?

Quien sin llegarse a valer

De honor que después sabrás

Es una mujer no más.

Heraclio:

¿Y qué más que una mujer?

$Y$ si todas son así,

¿Cómo hubo hombre que vivio?

Cintia:

$$
\text { Luego otras no has visto }
$$

Heraclio:

$$
\text { No.»11. }
$$

Aunque la confusión de la mujer con un animal está quizá más en la línea del ejemplo CCXXXI de El Libro de los enxemplos por a.b.c. de Clemente Sánchez de Vercial:

«Dicen que estando dos ermitannos asentados en su cella por una feniestra acatando, vieron pasar delante dellos una mujer bien vestida e bien afeitada; e el uno dellos que nunca viera mujer, demandó al otro qué cosa era, e dijole que era cabra; otros dicen que le dijo que era ojo del diablo. E él tanto amor hobo qe ella que a la noche non pudo cenar, e el compannero demandóle por qué non comía e respondible: que tant grand pietat habíe de aquella cabra, que non podíe comer.»12.

11 Pedro Calderón de la BarCa, «En esta vida todo es verdad y mentira», Obras de Pedro Calderón de la Barca, BAE 9, 54.

12 Clemente SANCHEZ DE VERCIAL, «Libro de los enxemplos por a.b.c.», Escritores anteriores al siglo $X V$, BAE 51, 504. 
De muy fieles al Barlaam se pueden calificar, en cambio, las versiones que encontramos en la Segunda comedia de Ceslestina (Trigésimoprimera cena) de Feliciano de Silva y en la Agudeza y arte de ingenio (Discurso LVII) de Baltasar Gracián. Cuenta este último la historia con mucho detalle, atribuyéndolsela a San Juan Damasceno13. Por otra parte, en El Criticón (Crisi IV, parte I) nos encontramos con el malhechor que es sepultado vivo en una profunda hoya llena de «sabandijas, dragones, tigres, serpientes y basiliscos»14, y con el extranjero que por allí pasa y que, conmovido por sus lamentos, aparta la losa que cubre la cueva. Sale entonces el tigre y lame las manos del buen hombre, la serpiente adora sus pies y lo mismo hacen los demás animales, «rindiéndose humildes y dándole las gracias de haberles librado de la compañía de un hombre ruin» 15 y aconsejándole que se marche de allí antes de que éste salga. Huyen las bestias a toda velocidad y el extranjero, asombrado, permanece inmóvil. Cuando sale el malhechor, lo primero que hace es asesinar a su liberador y robarle sus bienes. Esta historia, que sirve para demostrar que «no hay lobo, no hay león, no hay tigre, no hay basilisco que llegue al hombre: a todos excede en fiereza»16, procede del apologo del Calila titulado «Del orebz et del ximio et el texón et de la culebra et del religiosom 17 .

En Marcos Obregón (parte I, Descanso III) y en La niña de los embustes (cap. VI), encontramos un cuento muy difundido desde su aparición en la Disciplina clericalis y en el Sendebar, conocido por el nombre de «La espada» 18. La síntesis del argumento, que presenta numerosas variantes, es la siguiente: marido que llega inoportunamente y mujer astuta que coloca a su amante en la puerta de la casa con una espada en la mano; ante las preguntas del marido ella dice que el mancebo ha entrado huyendo de unos hombres que le querian matar, explicación que satisface al cornudo. En la obra de Vicente Espinel, Marcos

13 Sobre las distintas teorias acerca de la trasmisión y cristianización de la obra, vid. la Introducción de OLGA T. IMPEY y JOHN E. KEUER a la edición de Barlaam y Josafat hecha por JOHN E. KELLER y ROBERT W. LINKER (Madrid: CSIC, 1979), XI-XL. Para una revisión actual del problema, vid. PEdro BAdenas, Introducción, Barlaam y Josafat, XXI-XXXIV.

14 Baltasar Gractan, El Criticón, Ed. Santos Alonso, (Madrid: Catedra, 1980), 102.

15 Ibid., 103.

16 Ibid., 102.

17 Calila e Dimna, 316-322.

18 «Ejemplo de la espada», PEDro ALfonso, 122-123; «Gladius», Sendebar, Ed. Ma Jesús Lacarra, (Madrid: Cátedra, 1989), 92-93. Sobre la difusión de este cuento, vid. Sendebar, Ed. J. Fradejas Lebrero, (Madrid: Editora Nacional, 1981), 75-79; H. SCHWARZBAUM, \&International Folklore Motifs in Petrus Alphonsi's Disciplina Clericalis, Sefarad XXII (1962), 20-22; J. BEDIER, LES FABLAUX, 64 ed. (París: Champion 1982), 228-236; GASTON PARIS, \&Le Lai de l'epervier», Romania VII (1878), 1-21. 
ayuda a escapar al amante de la mujer del Dr. Sagredo, su amo, poniéndose a gritar, en la puerta de la calle, que le roban la capa, en vista de lo cual el marido burlado coge una espada y saie en persecución de los capeadores. El problema es que al amante, con los nervios, sólo le da tiempo a salir de su escondite pero no a abandonar la casa, de modo que Sagredo, cuando regresa, se lo encuentra. A sus preguntas, Marcos responde que el mozo había sido también víctima de los capeadores y que se había refugiado allí porque éstos le querían matar. Teresa de Manzanares, en la novela de Castillo Solórzano, al igual que lo hiciera Lorenza en el El viejo celoso, utiliza la estratagema para burlar la vigilancia de D. Lupercio de Saldaña, su marido, y meter en el hogar conyugal al Licenciado Sarabia, su amigo:

«Pues el día del concierto, ya de noche, que aún no habían cerrado las puertas de la casa, se entró por ellas el licenciado dando voces, que le favoreciesen, que le querian matar. Venían en su seguimiento cuatro amigos suyos bien puestos en armas con las espadas en blanco. Estaba el viejo en unos aposentos bajos donde él asistía a aquella hora a sus devociones. Pues como viese aquel hombre en su casa salió a favorecerle con la espada en blanco, dando voces a los que le seguian que le dejasen. Ellos (que ya estaban industriados en lo que habían de hacer) se salieron a la calle; el viejo cerro la puerta y llev6 a Sarabia a su aposento, el cual, fingiendo turbación, no acertaba a darle las gracias del socorro.»19.

Quedan dos hombres fuera de la casa, simulando esperar a Sarabia para matarlo; D. Lupercio y sus criados salen a espantarlos y pasan en su persecución toda la noche, mientras Teresa y el Licenciado se divierten.

Otra obra en la que la que se petentiza la presencia de viejos cuentos es las Novelas en verso de Cristobal de Tamariz. Así, en la novela titulada «Cuento de una burla que hizo una dama a un caballero que andava de tierra en tierra con un libro, escriuiendo faltas de mugeres, por vengarse de una de quien fue despreciado» se recrea, en parte, el «Enxenplo del mançebo que non quería casar fasta que sopiese las maldades de las mugeres» del Sendebar20, que cuenta cómo deja en ridículo una mujer casada a un mozo que, obsesionado por los engaños de las féminas, dedica su vida a escribir libros sobre el tema. Igualmente, vuelve los ojos Tamariz a la Disciplina clericalis cuyo «Ejem-

19 A. Castillo Solórzano, La niña de los embustes Teresa de Manzanares, Ed. D. Emilio Cotarelo y Mori, (Madrid: Librería de la Viuda de Rico, 1906), 90-91.

20 CRISTÓbal De TAMARZ, Novelas en verso, Ed. Donald McGrady, (Charlottesville, Virginia: Biblioteca Siglo de Oro, 1974), 187; «Enxenplo del mançebo...», Sendebar, 132-134. 
plo del medio amigo» da tema a su Novela 721 . Este cuento, muy difundido en la literatura medieval, narra la historia del mozo que presume de tener muchos amigos y del padre que, maravillado de que su hijo siendo tan joven haya conseguido tener tantos amigos cuando él, que es un anciano, sólo ha conseguido tener medio, le propone que los pruebe. A tal fin, hace que el chico mate un becerro, lo meta en un saco y vaya, con el saco al hombro, de amigo en amigo diciendo que lleva un hombre al que ha matado y al que quiere enterrar en secreto. Ni que decir tiene que, ante tamaño compromiso, todos los amigos se llaman andana, en vista de lo cual, el padre lo manda a casa de su medio amigo que, sin dudarlo un momento, entierra el saco en su propio jardín. La versión de Tamariz presenta algunas variantes pues es el padre el que mata el animal, un cebón en vez de un becerro, y entrega al hijo el saco ensangrentado haciéndole creer que contiene el cadáver de un hombre asesinado por él, luego, padre e hijo van juntos a la casa del medio amigo y cuando se descubre el contenido del saco se lo cenan entre los tres. Tenemos también el «Cuento de un gracioso caso sobre un portasgo que se pagava de qualquier persona que lleuaua alguna falta o defecto natural»22, inspirado (a través de La vida de YsoPet con sus fabulas historiadas, al decir de Donald McGrad23) en el «Ejemplo del versificador y el giboso» de la Disciplina clericalis 24 . Se trata del caso del poeta que pide al rey el privilegio de que las personas con defectos físicos que entren en la ciudad le paguen un impuesto. Un jorobado se niega a pagar y en la porfía se descubre que además de giboso es tuerto, tiñoso, sarnoso y cojo por lo que tiene que pagar cinco tasas, una por cada defecto. En el cuento de Tamariz son seis los defectos físicos y por lo tanto seis las tasas que ha de pagar el pobre corcovado.

Del Calila e Dimna proceden dos de las historias que cuenta Sebastián Mey en su Fabulario. La primera, titulada «El amigo desleal», es la conocida fábula de «los mures que comían hierro»: un mercader deja en depósito a un amigo suyo una buena cantidad de hierro; el amigo lo vende y cuando el mercader vuelve y reclama su hierro el depositario le contesta que se lo han comido los ratones... «El hombre falso y el torpe» inspira «El hombre verdadero y

21 «Ejemplo del medio amigo», PEDro Alfonso, 97-98. Sobre la difusión de este ejemplo, vid., entre otros, Charles PHILIP WAGNer, The Sources of «El Cavallero Cifar» (Paris: Extrait de la Revue Hispanique, 1903), 78-83; H. SCHWARZBAUM, «International Folklore Motifs...» Sefarad XXI (1961), 283-289; K.R. SCHOLBERG, *A Half- Friend and a Friend and a Half», Bulletin of Hispanic Studies XXXV (1978), 187-198; LOLA LOPEZ DfAZ, «La importancia de tener un medio amigo», LEER 69 (1993-1994), 62-64.

22 C. TAMARIZ, 181.

23 DONAld MCGrady, Introduccion, C. Tamariz, 45.

24 PEDRo Alfonso, 114-115. 
el mentiroso» de Mey: dos amigos encuentran una bolsa llena de dinero y el «falso y mentiroso» convence al utorpe y verdadero" de que lo mejor es enterrarla junto a un arbol. Ni que decir tiene que «el falson desentierra la bolsa por su cuenta y se queda con todo el dinero. Cuando «el torpe» propone rescatar el tesoro y van los dos al pie del árbol y descubren que ha desaparecido, «el mentiroso» inculpa al «verdadero», lo lleva ante la justicia y, tras una serie de peripecias la verdad acaba por resplandecer25.

En fin... es tarea ardua, si no imposible, agotar la materia y eso que me he limitado a rastrear algunos de los cuentecillos recogidos en cuatro obras: Disciplina clericalis, Calila e Dimna, Sendebar y Barlaam y Josafat. Pero aunque el estudio no sea exhaustivo y aunque la relación entre las colecciones medievales y las obras comentadas no sea, por lo general, directa ni fácil de establecer26, creo que los casos presentados dan cumplida idea de la vitalidad, vigencia y capacidad de adaptación que en los siglos XVI y XVII conservaban todavía los viejos cuentos orientales. Y dan cumplida idea también de cómo los escritores de aquellas centurias -los grandes y los no tan grandes- bebían una y otra vez en ese manantial inagotable. Manantial inagotable al que Cervantes, Lope, Tamariz, Timoneda, Espinel o Gracián... acudían en busca de ejemplos de sensatez, buen humor, sentido comun, gracia, astucia o herósmo... manantial inagotable en el que encontraban historias que a ellos y a su público debian de resultarles muy gratas como muy gratas nos resultan a los lectores de estas postrimerías de milenio.

25 Cfr. «Los mures que comian hierro* Calila e Dimna, 175-178; «El hombre falso y torpe», ibid., 171-173, y SEBATAN MEY, Fabulario, Ed. Carmen Bravo-Villasante, (Madrid: Fundación Universitaria Española, 1975), 16-22 y 65-75.

26 A este respecto vid. MARla Jesús LACARRA, «Pervivencia y trasmisión del cuento medieval en la Edad de Orow, Actas del I Congreso Intemacional de Hispanistas del Siglo de Oro. Ed. por PABlo JAURALDE, DOLORES NOGUERA y ALFONSO REY (Londres: Tamesis Books, 1990), 261-269. 